\title{
ЭЛЕМЕНТНЫЙ СОСТАВ ЛИШАЙНИКА Rhizocarpon НА КАМНЕ КАК ИНДИКАТОР ПЕРЕНОСА ЗАГРЯЗНЯЮЩИХ ВЕЩЕСТВ НА ТЕРРИТОРИЮ АЛТАЯ
}

\author{
Робертус Юрий Владимирович 1 , \\ ariecol@mail.gorny.ru
}

\author{
Рихванов Леонид Петрович2, \\ rikhvanov@tpu.ru
}

Юсупов Дмитрий Валерьевич yusupovd@mail.ru

\author{
Кивацкая Анна Васильевна ${ }^{1}$, \\ ariecol@mail.gorny.ru
}

\section{Ситникова Валентина Александровна ${ }^{4}$, valya_90_well@mail.ru}

\section{Большунова Татьяна Сергеевна 5 , BolshunovaTS@gmail.com}

\author{
Любимов Роман Владимирович1, \\ ariecol@mail.gorny.ru \\ 1 Институт водных и экологических проблем СО РАН, \\ Россия, 656038, г. Барнаул, ул. Молодежная, 1. \\ 2 Национальный исследовательский Томский политехнический университет, \\ Россия, 634050, г. Томск, пр. Ленина, 30. \\ 3 Амурский государственный университет, \\ Россия, 675027, г. Благовещенск, Игнатьевское шоссе, 21. \\ 4 Алтайский региональный институт экологии, \\ Россия, 649100, Республика Алтай, с. Майма, ул. Заводская, 54. \\ 5 АО «ТомскНИПИнефть», \\ Россия, 634027, г. Томск, пр. Мира, 72.
}

\begin{abstract}
Актуальность работы обусловлена необходимостью изучения экологических последствий многолетнего трансграничного переноса загрязняющих веществ из индустриальных центров Восточного Казахстана на территорию Алтайского края и Республики Алтай.

Цель: определить элементный состав и особенности распределения химических элементов в эпилитном лишайнике Rhizocarpon geographicum (L.) DC. на камне как биогеохимическом индикаторе специфики и интенсивности трансграничного переноса загрязняющих веществ на территорию Алтая.

Memoды: отбор образцов лишайника Rhizocarpon geographicum (L.) DC. на скальных обнажениях нижнепалеозойских терригенных пород для определения содержания в них ртути методом атомной абсорбции и 28 химических элементов методом инструментального нейтронно-активационного анализа, обработка полученных данных методами прикладной статистики. Результаты. Впервые получены данные об уровнях содержания и особенностях распределения комплекса химических элементов в лишайнике Rhizocarpon geographicum (L.) DC. на камне на территории Алтая. Проведено сравнение данных с региональным фоном и кларком в биосфрере. Установлено наличие двух групп элементов в лишайнике - микроэлементов неорганической пыли и ассоциации химических элементов полиметаллических руд ( $\mathrm{Zn}, \mathrm{As}, \mathrm{Sb}, \mathrm{Br}, \mathrm{Hg}, \mathrm{Au})$. Приведена аргументация в пользу преобладающего поступления элементов второй ассоциации в лишайник Rhizocarpon из атмосфрерных выпадений, переносимых с территории Восточного Казахстана. Выявлена обширная площадь повышенных концентраций изученных элементов в лишайнике Rhizocarpon, пространственно совпадающая с ранее установленной областью загрязнения снежного и растительного покрова на территории региона. Сделан вывод о пригодности элементного состава эпилитного лишайника Rhizocarpon на камне в качестве биогеохимического индикатора специфики и интенсивности трансграничного переноса загрязняющих веществ на территорию Алтая.
\end{abstract}

\section{Ключевые слова:}

Горный Алтай, трансграничный перенос, лишайник Rhizocarpon на камне, элементный состав, биогеохимический индикатор.

\section{Введение}

В литературе накипные лишайники, обитающие на выходах горных пород (скалы, отдельные глыбы), выделяются в отдельную группу эпилитной лихенофлоры. Особенностями этой группы лишайников являются: медленный постоянный рост, долголетие, аэральное питание, безбарьерное накопление загрязняющих веществ [1-4]. Это делает их чувствительным биогеохимическим индикатором качества приземного атмосферного воздуха и позволяет по ним картографировать зоны многолетнего поступления поллютантов в окружающую среду [5-17].

Полученные в последнее время данные по факту загрязнения снегового и растительного (листья тополя, годовые кольца лиственницы) покровов показывают, что на территорию Горного Алтая (Республика Алтай и Алтайский край) в течение длительного периода в результате трансграничных переносов выбросов загрязняющих веществ выпадает определенный спектр тяжелых металлов и токсичных элементов, ком- 
понентов полиметаллических руд, перерабатываемых металлургическими предприятиями Восточного Казахстана - Усть-Каменогорским свинцово-цинковым, Зыряновским свинцовым и Лениногорским полиметаллическим комбинатами $[18,19]$.

С учетом этого обстоятельства, авторами была изучена возможность дополнительной оценки специфики атмосферных выпадений выбросов от этих предприятий на территории Горного Алтая по элементному составу обитающих на выходах горных пород эпилитных лишайников.

\section{Материалы и методы}

Объектом изучения служили покрытые эпилитными лишайниками скальные выходы горных пород в основном кембро-ордовикского возраста (катунская, кудатинская и сайлюгемская свиты горноалтайской серии). Для достижения однородности химического состава литогенного субстрата выбирались главным образом обнажения терригенных пород (песчаники, алевролиты, алевролито-песчаники), на которых преобладали кальцефобные виды накипных лишайников.

Изученная территория относится к западной части Республики Алтай, непосредственно граничащей с Восточно-Казахстанской областью (ВКО). Лишайники опробованы в 10 точках на трех ориентированных на северо-запад профилях, удаленных от населенных пунктов и автодорог более чем на 0,5 км. Расстояние между профилями составило 50-60 км, а между точками - 35-50 км (рис. 1).

Всего в западной части Республики Алтай было отобрано 10 образцов доминирующего на обнажениях терригенных пород накипного литофильного лишай- ника Ризокарпон географический (Rhizocarpon geographicum (L.) DC.), представленного мелкими (1-3 мм), преимущественно накипными (корковыми) агрегатами. Отдельные его экземпляры имеют по периферии венчик из рассечённых пластинок, что позволяет относить Ризокарпон также и к листоватым лишайникам. Его расселение на каменном субстрате различно. Нередко он занимает большие площади, придавая им характерную бледно-зеленовато-серую окраску (рис. 2). Как правило, с Rhizocarpon geographicum (L.) DC. в подчиненном количестве соседствуют до 3-5 видов других эпилитных лишайников.

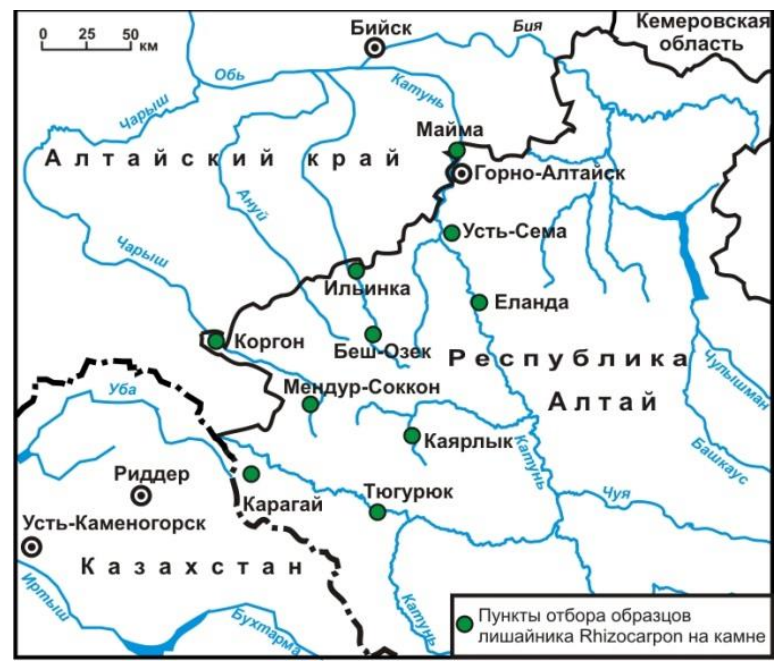

Puc. 1. Схема отбора образиов лишайника Rhizocarpon на территории Алтая

Fig. 1. Scheme of sampling the lichen Rhizocarpon on the territory of Altai
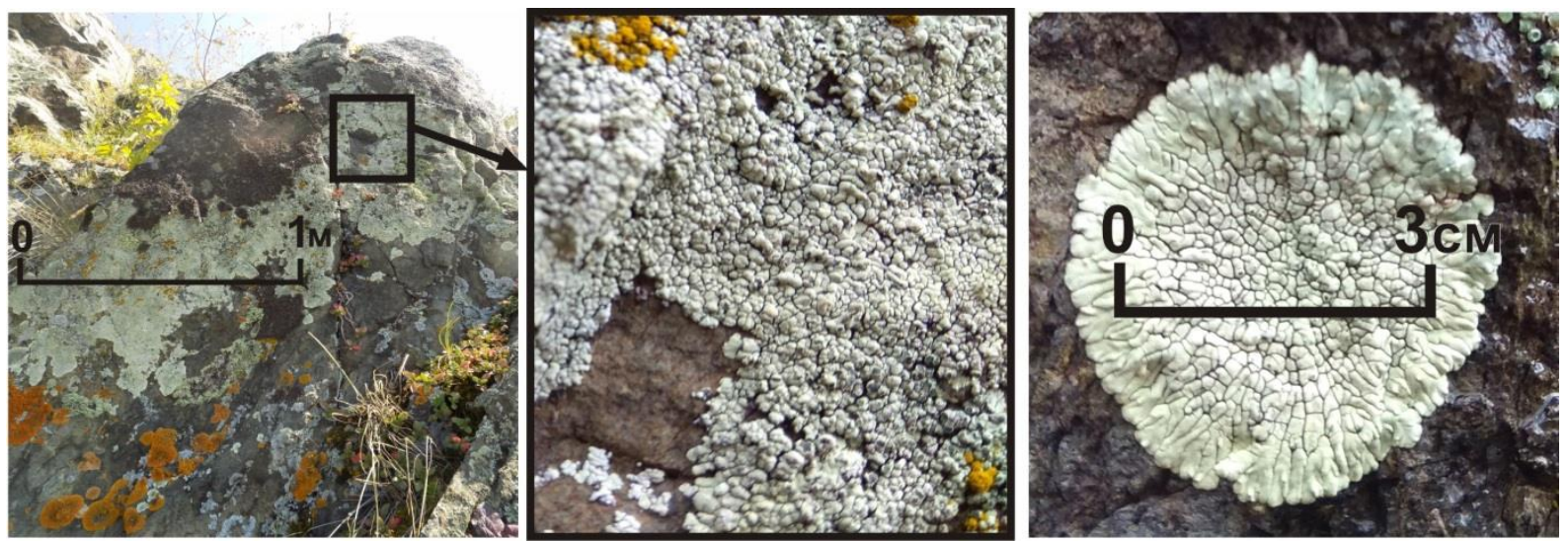

Puc. 2. Скопления накипного литайника Rhizocarpon geographicum (L.) DC. на обнажении песчаников близ c. УстьСема. Справа строение отдельного слоевища лишайника

Fig. 2. Accumulations of scale lichen Rhizocarpon geographicum on the outcrop of sandstones near the village Ust-Sema. On the right is the structure of a separate lichen strata

Отбор образцов проводился в сухую погоду специальным ножом-скребком. Взятый материал просматривался под микроскопом и очищался от породы. Подготовка образцов к анализам заключалась в истирании материала.

Элементный состав образцов лишайника (28 элементов) изучен в ядерно-геохимической лаборатории мето- дом инструментального нейтронно-активационного анализа (ИНАА) на исследовательском реакторе ИРТ-Т в Томском политехническом университете (аналитик А.Ф. Судыко). Определение содержания ртути выполнено методом атомной абсорбции (пиролиза) на ртутном анализаторе «РА-915+» с приставкой «ПИРО-915+» в Международном инновационном 
научно-образовательном центре «Урановая геология» в Томском политехническом университете (аналитик Е.М. Турсуналиева). Для контроля точности определения ртути и элементов ИНАА использовался стандартный образец состава листа березы ЛБ-1 (ГСО 8923-2007).

Элементный состав каменного субстрата (пород горноалтайской серии) в местах отбора лишайника был изучен АО «Горно-Алтайская экспедиция» методом ISP-MS при геологическом доизучении площадей масштаба 1:200000 на территории Горного Алтая.

По данным анализов рассчитаны статистические параметры, коэффициенты (Кс) и кларки (Кк) концентрации относительно регионального фона и биосферы соответственно, определены корреляционные связи элементов в лишайнике.

\section{Результаты и их обсуждение}

Известно, что лишайники - это группа организмов биоиндикаторов, которые обитают преимущественно только в экологически чистых местах. К числу таких мест относится территория Горного Алтая, где отсутствуют крупные промышленные предприятия, а основной отраслью экономики является сельское хозяйство с преобладающим экстенсивным животноводством. Эти обстоятельства способствуют широкому развитию разнообразных эпилитных лишайников на обнажениях и элювиально-делювиальных развалах горных пород.

Впервые оцененное содержание микроэлементов (МЭ) в лишайнике Rhizocarpon geographicum (L.) DC. на территории Западного Алтая характеризуется в целом низкими значениями, умеренной вариабельностью (в основном до $50 \%$ ), превышением регионального фона в 2-14 раз (в среднем в 6 раз). Среднее содержание большинства изученных МЭ в 1,5-5 раз ниже их кларка в биосфере [20], кроме кальция, бария, стронция, цинка, мышьяка, сурьмы, брома, ртути и золота, среднее содержание которых в 1,1-8,6 раза (в среднем в 3,5 раза) выше кларковых значений (табл. 1).

Для изученных МЭ в литогенном субстрате - терригенных породах горноалтайской серии - присущи в целом невысокие концентрации и слабая их вариабельность, а также низкое превышение регионального фона - от 1,2 до 4 ед., при среднем значении 2,2 ед. Характерно, что для упомянутой ассоциации МЭ $(\mathrm{Ca}$, $\mathrm{Zn}, \mathrm{As}, \mathrm{Sb}, \mathrm{Br}, \mathrm{Hg}$, Au) проявлены максимальные значения отношения их содержания в лишайнике и породном субстрате (2-4,7 ед.), что указывает на их дополнительное поступление в лишайник (табл. 1).

Большинство МЭ в лишайнике Rhizocarpon geographicum (L.) DC. имеют между собой тесные положительные связи, которые составляют более 50 \% от их общего числа. Наибольшее число таких связей характерно для редкоземельных и литофильных МЭ, в том числе для породообразующих макроэлементов (кроме кальция).

На этом фоне в лишайнике выделяется вышеотмеченная ассоциация МЭ, представленная цинком, мышьяком, сурьмой, бромом, ртутью, золотом, то есть типоморфными элементами полиметаллических ме- сторождений Рудного Алтая. Для них характерно отсутствие корреляционных связей или их небольшое число (в основном между собой). Другой чертой этой ассоциации является наличие преимущественно отрицательных связей с редкоземельными и литофильными МЭ (табл. 2), что указывает на разные «носители» этих групп микроэлементов в изученный лишайник. Для РЗЭ и литофильных МЭ это неорганическая пыль, для рудных МЭ - выбросы предприятий.

Таблица 1. Содержание элементов в лишайнике Rhizocarpon geographicum (L.) DC. и его литогенном субстрате на территории Алтая, мг/кг

Table 1. Contents of elements in the lichen Rhizocarpon geographicum (L.) DC. and its lithogenic substrate on the territory of Altai, $\mathrm{mg} / \mathrm{kg}$

\begin{tabular}{|c|c|c|c|c|c|c|c|c|}
\hline \multirow{2}{*}{ 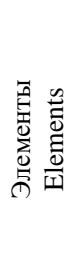 } & \multicolumn{4}{|c|}{$\begin{array}{c}\text { Лишайник (n=10) } \\
\text { Lichen Rhizocarpon } \\
\text { geographicum (L.) DC. }\end{array}$} & \multicolumn{3}{|c|}{$\begin{array}{c}\text { Литогенный } \\
\text { субстрат }(\mathrm{n}=25) \\
\text { Lithogenic substrate }\end{array}$} & \multirow{2}{*}{ 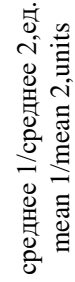 } \\
\hline & 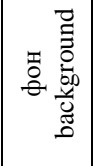 & 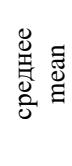 & 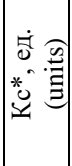 & 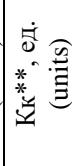 & 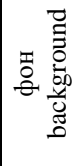 & 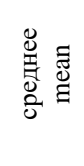 & 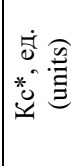 & \\
\hline Ca, \% & 0,8 & 4,00 & 5,0 & 2,50 & 1 & 1,65 & 1,6 & 2,42 \\
\hline $\mathrm{Na}, \%$ & 0,1 & 0,37 & 3,7 & 0,19 & 1,5 & 2,47 & 1,6 & 0,15 \\
\hline $\mathrm{Fe}, \%$ & 0,2 & 1,19 & 5,9 & 0,54 & 2 & 3,90 & 1,9 & 0,30 \\
\hline $\mathrm{Cr}$ & 0,3 & 23,7 & 7,9 & 0,47 & 50 & 111 & 2,2 & 0,21 \\
\hline Co & 0,5 & 4,74 & 9,5 & 0,22 & 10 & 19,1 & 1,9 & 0,25 \\
\hline $\mathbf{Z n}$ & 5 & 36,7 & 7,3 & 0,80 & 10 & 16,0 & 1,6 & 2,29 \\
\hline $\mathrm{Ba}$ & 30 & 102 & 3,4 & 2,84 & 150 & 431 & 2,9 & 0,24 \\
\hline $\mathrm{Sr}$ & 20 & 87,0 & 4,4 & 2,17 & 50 & 185 & 3,7 & 0,47 \\
\hline Cs & 0,2 & 1,17 & 5,8 & 0,19 & 2 & 3,90 & 2,0 & 0,43 \\
\hline $\mathrm{Sc}$ & 0,8 & 4,10 & 5,1 & 0,59 & 10 & 16,4 & 1,6 & 0,25 \\
\hline $\mathrm{La}$ & 2 & 8,37 & 4,2 & 0,84 & 10 & 22,8 & 2,3 & 0,37 \\
\hline $\mathrm{Lu}$ & 0,05 & 0,15 & 3,0 & 0,37 & 0,2 & 0,36 & 1,8 & 0,40 \\
\hline $\mathrm{Ce}$ & 10 & 21,3 & 2,1 & 0,71 & 20 & 46,6 & 2,3 & 0,46 \\
\hline $\mathrm{Hf}$ & 0,2 & 1,52 & 7,6 & 0,76 & 2 & 3,97 & 2,0 & 0,38 \\
\hline $\mathrm{Ta}$ & 0,05 & 0,22 & 4,4 & 0,11 & 0,3 & 0,71 & 2,4 & 0,32 \\
\hline $\mathrm{Yb}$ & 0,2 & 0,90 & 4,5 & 0,45 & 1,5 & 2,46 & 1,6 & 0,36 \\
\hline $\mathrm{Nd}$ & 1 & 7,68 & 7,7 & 0,77 & 20 & 23,7 & 1,2 & 0,32 \\
\hline As & 0,25 & 3,41 & 13,6 & 1,14 & 5 & 1,20 & 2,4 & 2,84 \\
\hline Sb & 0,15 & 2,15 & 14,3 & 8,58 & 4 & 1,00 & 2,5 & 2,14 \\
\hline $\mathrm{Br}$ & 1 & 4,49 & 4,5 & 0,17 & 0,3 & 1,00 & 3,3 & 4,49 \\
\hline $\mathbf{A u}$ & 0,0005 & 0,005 & 10,0 & 7,14 & 0,001 & 0,0025 & 2,5 & 2,00 \\
\hline $\mathbf{H g}$ & 0,05 & 0,22 & 4,2 & 1,10 & 0,01 & 0,04 & 4,0 & 4,73 \\
\hline Th & 0,5 & 2,10 & 4,2 & 0,26 & 4 & 6,93 & 1,7 & 0,30 \\
\hline $\mathrm{U}$ & 0,1 & 0,70 & 7,0 & 0,35 & 1 & 1,93 & 1,9 & 0,36 \\
\hline
\end{tabular}

* - среднее содержание относительно регионального фона, ** - то же кларка элементов в биосфере [20]. Жирным шрифтом выделены микроэлементы, накапливаюшиеся в лишайнике Rhizocarpon.

* - average content relative to the regional background, ** - the same clarke of elements in the biosphere [20]. The elements accumulating in the lichen are marked in bold.

Отметим, что и в других компонентах природной среды, в частности в снеготалой воде, снеговой пыли, а также в золе листьев тополя (Populus laurifolia Ledeb.), корреляционные связи вышеотмеченных рудных МЭ в целом заметно слабее, чем у породных МЭ, что также указывает на различные источники поступления этих двух ассоциаций на территорию Алтая [19]. 
Таблица 2. Характер корреляционных связей МЭ в лишайнике Rhizocarpon geographicum

Table 2. Nature of correlations of microelements in the lichen Rhizocarpon geographicum (L.) DC.

\begin{tabular}{|l|l|l|l|l|l|l|l|l|l|l|l|l|l|l|l|}
\hline $\mathbf{C a}$ & $\mathrm{Na}, \mathrm{Fe}$ & $\mathrm{Cr}$ & $\mathrm{Co}$ & $\mathbf{Z n}$ & $\mathrm{Ba}, \mathrm{Sr}$ & $\mathrm{Cs}$ & $\mathrm{P} 3$ & $\mathrm{Sc}$ & $\mathbf{A s}$ & $\mathbf{S b}$ & $\mathbf{B r}$ & $\mathbf{A u}$ & $\mathbf{H g}$ & $\mathrm{Th}$ & $\mathrm{U}$ \\
\hline
\end{tabular} Число положительных корреляционных значимых связей между МЭ ( $\mathrm{p} \geq 0,05)$ в лишайнике, \%

Number of positive correlation of significant relationships between trace elements $(\mathrm{p} \geq 0,05)$ in lichen, \%

\begin{tabular}{|l|l|l|l|l|l|l|l|l|l|l|l|l|l|l|l|}
\hline 22 & 70 & 59 & 52 & 0 & 59 & 25 & 70 & 70 & 11 & 7 & 0 & 0 & 4 & 43 & 59 \\
\hline
\end{tabular}

Число отрицательных корреляционных связей между МЭ в лишайнике, \%

Number of negative correlations between trace elements in lichen, $\%$ \begin{tabular}{|l|l|l|l|l|l|l|l|l|l|l|l|l|l|l|l|}
15 & 7 & 15 & 7 & 35 & 11 & 26 & 11 & 11 & 37 & 59 & 56 & 81 & 44 & 11 & 15 \\
\hline
\end{tabular}

Жирным шрифтом выделены микроэлементы с минимальным числом значимых корреляционных связей.

The trace elements with a minimum number of significant correlations are marked in bold.

Такая же особенность проявлена и для талой воды ледника Большой Актру, где МЭ состава полиметаллических руд имеют корреляционные положительные связи между собой и отрицательные - с породными элементами. При этом число их значимых связей на порядок меньше, чем у породных МЭ. По мнению [21], это указывает на раздельное поступление характеризуемых ассоциаций на территорию региона.

Содержание рудных МЭ в золе листьев тополя (Populus laurifolia Ledeb.) - одного из наиболее представительных биогеохимических индикаторов антропогенного воздействия в Западном Алтае - в 3-6 раз выше регионального фона (породных МЭ не более чем в 2 раза) [22]. Еще более контрастные значения проявлены для отношения средних концентраций рудных МЭ в золе листьев тополя в г. УстьКаменогорске (место локации основных источников выбросов рудных МЭ) и на территории Западного Алтая (табл. 3).

Пространственно совпадающие между собой области повышенного содержания как рудных, так и породных МЭ в лишайнике Rhizocarpon geographicum
(L.) DC. образуют на изученной территории языкообразный зонально построенный биогеохимический мегаореол, вытянутый в северо-восточном и частично в восточном направлении, согласно преобладающим ветрам. На территории Западного Алтая его площадь составляет до 25 тыс. км², длина более 300 км при средней ширине 100-120 км. Границы этого мегаореола, как правило, слабо и умеренно контрастные.

Таблица 3. Содержание МЭ в золе листьев тополя в Восточно-Казахстанской области и в 3 ападном Алтае, мг/кг [3]

Table 3. Content of microelements in the ash of the poplar leaves in East Kazakhstan and in West Altai, $\mathrm{mg} / \mathrm{kg}$ [3]

\begin{tabular}{|c|c|c|c|c|c|c|c|c|}
\hline \multirow{3}{*}{$\begin{array}{c}\text { Показатели } \\
\text { Parameters }\end{array}$} & \multicolumn{8}{|c|}{ Микроэлементы/Trace elements } \\
\hline & \multicolumn{4}{|c|}{$\begin{array}{c}\text { Породные } \\
\text { Rock }\end{array}$} & \multicolumn{4}{|c|}{\begin{tabular}{|c|} 
Рудные \\
Ore \\
\end{tabular}} \\
\hline & $\mathrm{Cr}$ & $\mathrm{Ce}$ & $\mathrm{Sr}$ & $\mathrm{Co}$ & $\mathbf{Z n}$ & Cd & As & Sb \\
\hline $\begin{array}{l}\text { Среднее, Алтай } \\
\text { Mean, Altai }\end{array}$ & 1,8 & 1,02 & 910 & 3,4 & 60 & 2,8 & 0,5 & 0,3 \\
\hline $\begin{array}{l}\text { Региональный фон Алтая } \\
\text { Altai regional background }\end{array}$ & 1,0 & 0,5 & 500 & 2,0 & 20 & 0,7 & 0,1 & 0,05 \\
\hline $\begin{array}{l}\text { Среднее/фон, ед. } \\
\text { Mean/background, units }\end{array}$ & 1,8 & 2,0 & 1,8 & 1,7 & 3,0 & 4,0 & 5,0 & 6,0 \\
\hline $\begin{array}{l}\text { Среднее, Усть-Каменогорск } \\
\text { Mean, Ust-Kamenogorsk }\end{array}$ & 2,9 & 1,87 & 1254 & 7,7 & 3090 & 39,3 & 2,5 & 2,1 \\
\hline $\begin{array}{l}\text { Усть-Каменогорск/Алтай, ед. } \\
\text { Ust-Kamenogorsk/Altai, units }\end{array}$ & 1,6 & 1,8 & 2,5 & 2,3 & 51,5 & 14,0 & 5,0 & 7,0 \\
\hline
\end{tabular}

Жирным шрифтом выделены микроэлементы, накапливаюшиеся в листьях тополя в ВКО и на Алтае.

The trace elements accumulating in poplar leaves in East Kazakhstan region and Altai are marked in bold.

Пространственное положение, морфология и внутреннее строение этого мегаореола в целом совпадает с ранее установленной на территории Алтая областью повышенных концентраций элементов полиметаллических руд в снеговой пыли, для которых также проявлена тенденция уменьшения содержания при удалении от восточной границы ВосточноКазахстанской области (рис. 3).
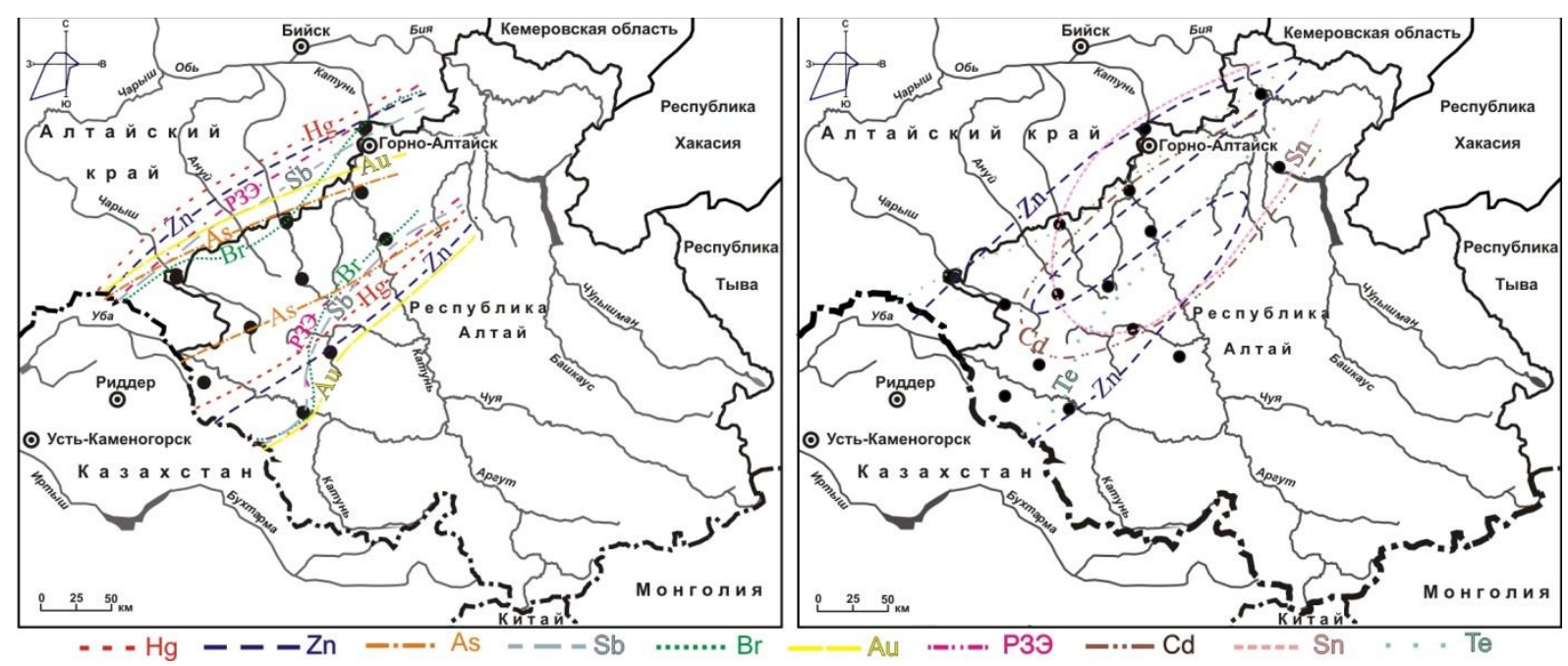

Pис. 3. Характер распределения МЭ в лишайнике Rhizocarpon geographicum (слева) и в снеговой пыли (справа) на территории Алтая

Fig. 3. Nature of distribution of microelements in the lichen Rhizocarpon geographicum (left) and in snow dust (right) in the Altai territory 
Идентичная ситуация характерна для областей повышенных (пониженных) концентраций МЭ и макрокомпонентов в снеготалой воде, золе листьев тополя, годичных кольцах лиственницы сибирской [19]. Обобщенная картина загрязнения этих и других депонирующих природных сред в результате воздушного переноса химических элементов и их соединений указывает на предприятия цветной металлургии ВКО как вероятный источник их поступления на территорию Алтая (рис. 4).

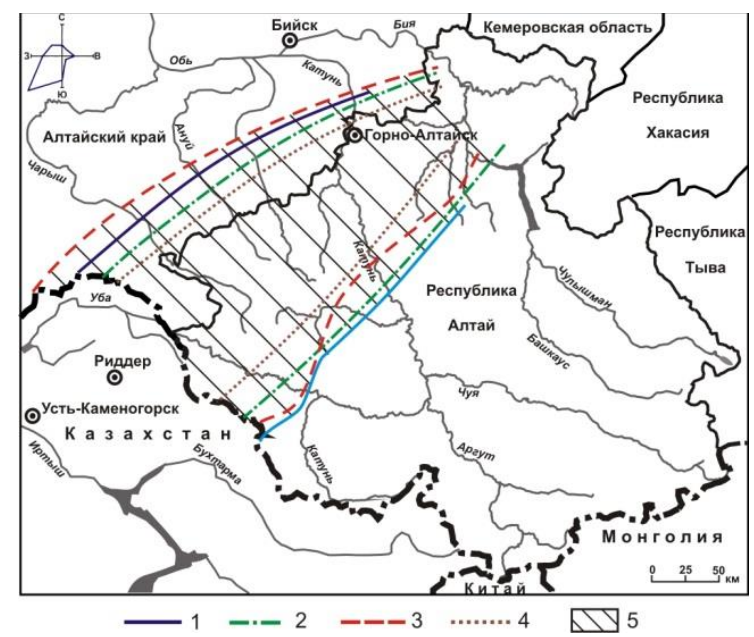

Рис. 4. Обобщенные ореоль МЭ в компонентах природной среды на территории Алтая. Обобщенные контуры загрязнения: 1 -лишайника Rhizocarpon geographicuт, 2 - снеговой пыли, 3 - листьев тополя черного, 4 - снеготалой воды; 5 - обобщенная область загрязнения природной среды

Fig. 4. Generalized areas of microelements in the components of the natural environment. Generalized pollution contours: 1 - Rhizocarpon geographicum lichen, 2 - snow dust, 3 - black poplar leaves, 4 snow melt water; 5 - generalized area of environmental pollution

Следует отметить, что проблема аэрогенного переноса на территорию Алтая тяжелометалльных поллютантов, содержащихся в выбросах металлургических предприятий Восточно-Казахстанской области, изучена недостаточно. Тем не менее, имеются достоверные данные об аномально высоком присутствии типоморфных элементов полиметаллических руд в талой воде ледников региона (Белуха, Бол. Актру и др.) [21], в годичных кольцах древесных видов [23], а также в природных планшетах атмосферных выпадений - в снеговом, растительном и почвенном покровах $[19,24]$.

Так, ранее проведенными эпизодическими исследованиями установлено, что в снеговом покрове на сопредельной с Восточно-Казахстанской областью территории Алтая проявлена область пониженных значений $\mathrm{pH}$ и повышенных концентраций сульфатов, соединений азота и основных химических элементов полиметаллических руд, что указывает на кислотный характер формирующих трансграничных атмосферных выпадений (из-за присутствия окисленной серы и азота) [19].
Имеющиеся данные позволяют в общем виде провести реконструкцию геоэкологических последствий многолетнего трансграничного переноса загрязняющих веществ на территорию Алтая, в том числе установить положение генерализованного следа атмосферных выпадений, оценить их хронологию, спектр и интенсивность.

Таким образом, геохимический отклик природной среды Алтая на привнос охарактеризованной ассоциации поллютантов с территории Восточно-Казахстанской области носит всеобъемлющий характер, в разной степени проявленный во всех транслирующих и депонирующих загрязнение средах. Для его достоверной оценки необходимо проведение полноценных исследований, включающих кроме комплекса геохимических исследований изучение состава, особенностей переноса и выпадения «высотных» и приземных аэрозолей.

Необходимо также отметить, что фактор трансграничного переноса загрязняющих веществ на территории Алтая является одной из приоритетных экологических проблем региона, что предполагает необходимость полноценной оценки его последствий.

\section{Выводы}

На основании вышеизложенных данных можно сделать следующие выводы:

1. Элементный состав эпилитного лишайника Rhizocarpon geographicum (L.) DC., развитого на обнажениях терригенных пород на смежной с Boсточным Казахстаном территории Западного Алтая, представлен в основном ассоциацией литофильных и редкоземельных элементов неорганической пыли и типоморфной ассоциацией микроэлементов ( $\mathrm{Zn}, \mathrm{As}, \mathrm{Sb}, \mathrm{Hg}, \mathrm{Au}, \mathrm{Br}$ и др.), содержащихся в выбросах предприятий цветной металлургии Восточно-Казахстанской области.

2. Области повышенных концентраций ассоциаций МЭ в лишайнике Rhizocarpon geographicum (L.) DC. пространственно совпадают с обширным ореолом наложенного загрязнения снегового, почвенного и растительного покровов и наиболее интенсивно проявлены на приграничной с Казахстаном территории Алтая.

3. Элементный состав лишайника Rhizocarpon geographicum (L.) DC. и, вероятно, других эпилитных лишайников на камне является биогеохимическим индикатором специфики, интенсивности прошлой и современной антропогенной деятельности, а также может использоваться в качестве дополнительного метода при изучении и мониторинге состояния приземной атмосферы.

4. Приведенные данные и материалы ранее проведенных исследований дают основание считать, что в результате многолетнего трансграничного переноса выбросов предприятий металлургического цикла Восточно-Казахстанской области на территории Западного Алтая сформировалась область загрязнения компонентов природной среды, медико-экологические последствия которого нуждаются в дальнейшем углубленном изучении. 


\section{Список литературы}

1. Кузнецова В.Ф. Эпифитные лишайники как индикаторы загрязнения атмосферного воздуха газообразными поллютантами, тяжелыми металлами и радионуклидами: автореф. дис. ... канд. наук. - Нижний Новгород, 2004. - 24 с.

2. Richardson D.H.S. Pollution monitoring with lichens. Naturalists' handbooks. - Slough: Richmond Publishing, 1992. - 19 p.

3. Сафранкова Е.А. Комплексная лихеноиндикация общего состояния атмосферы урбоэкосистем: дис. ... канд. наук. Брянск, 2014. - 204 с.

4. Richardson D.H.S. Understanding the pollution sensitivity of lichens // Botanical Journal of the Linnean Society. - 1988. V. $96 .-$ P. 31-43.

5. Biogeochemical characteristics of epiphitic lichen Lobaria pulmonaria of the Barguzin nature reserve (the Republic of Buryatia, Russia) / T. Bolshunova, L. Rikhvanov, A. Mezhibor, L. Zhornyak, N. Baranovskaya, E. Eremina // Journal of Environmental Engineering and Landscape Management. 2018. - V. 26. - № 2. - C. 120-127.

6. Элементный состав лишайника на шифере как биоиндикатор загрязнения атмосферы агломерации г. Горно-Алтайска / Ю.В. Робертус, Л.П. Рихванов, В.А. Ситникова, К.С. Савенко, Т.С. Большунова // Известия ТПУ. Инжиниринг георесурсов. -2018 . - Т. 329. - № 4. - C. 70-78.

7. Bargagli R. Moss and lichen biomonitoring of atmospheric mercury: a review // Science of the Total Environment. - 2016. V. 572. - P. 216-231.

8. Conti M.E., Cecchetti G. Biological monitoring: lichens as bioindicators of air pollution assessment - a review // Environmental Pollution. - 2001. - V. 114 (3). - P. 471-492.

9. Rossbach M., Lambrecht S. Lichens as biomonitors: global, regional and local aspects // Croatica Chemica Acta. - 2006. V. $79(1)$. - P. 119-124.

10. Monitoring air quality using lichens in Ghelyabinsk, Russia Federation / A.M. Kostryukova, T.G. Krupnova, I.V. Mashkova, E.E. Schelkanova // International Journal of GEOMATE. 2017. - V. 12. - № 34. - P. 101-106.

11. Lichen monitoring as a potential tool in environmental forensics: case study of the $\mathrm{Cu}$ smelter and former mining town of Karabash, Russia / O.W. Purvis, B.J. Williamson, B. Spiro, V. Udachin, I.N. Mikhailova, A. Dolgopolova // Geological Society, London, Special Publications. - 2013. - V. 384. - P. 133-136.

12. Bozkurt Z. Determination of airborne trace elements in an urban area using lichens as biomonitor // Environmental monitoring and assessment. - 2017. - V. 189. - № 11. - P. 1-12. DOI: 10.1007/s10661-017-6275-x

13. Vasilevich M.I., Vasilevich R.S. Features of heavy metal accumulation by epiphytic lichens in background areas of the taiga zone in the European northwest of Russia // Russian Journal of Ecology. - 2018. - V. 49. - № 1. - P. 14-20.

14. Koroleva Y., Revunkov V. Air pollution monitoring in the southeast Baltic using the epiphytic lichen Hypogymnia physodes // Atmosphere. - 2017. - V. 8. - № 7. - P. 1-12.

15. Will-Wolf S., Jovan S., Amacher M.C. Lichen elements as pollution indicators: evaluation of methods for large monitoring programmes // The lichenologist. - 2017. - V. 49. - № 4. P. 415-424.

16. Assessing atmospheric pollution in a petrochemical industrial district using a lichen-air quality index (IIAQI) / C. Boonpeng, W. Polyiam, K. Boonpragob, C. Sriviboon, D. Sangiamdee, S. Watthana // Ecological indicators. - 2018. - V. 95. - P. 589-594.

17. De Nicola F., Adamo P., Giordano S. Comparison of lichen and moss bags as monitoring devices of airborn trace elements and PAHs / Biomonitoring of air pollution using mosses and lichens: a passive and active. Approach state of the art research and perspectives. - New York: Nova Science Publishers, 2016. P. $177-194$.

18. Данилова Н.Г., Чапаева Г.В. Экологический мониторинг состояния окружающей среды Восточно-Казахстанской области в 1999 году // Наш общий дом: Матер. межд. конф. - Барнаул, 2000. - C. 27-29.

19. Индикация компонентами природной среды трансграничного переноса загрязняющих веществ на территорию Горного Алтая / Ю.В. Робертус, В.Н. Удачин, Л.П. Рихванов, А.В. Кивацкая, Р.В. Любимов, Д.В. Юсупов // Известия ТПУ. - 2016. T. 327. - № 9. - C. 39-48.

20. Иванов В.В. Экологическая геохимия элементов: Справочник. В 6 кн. - М.: Недра, 1996. - Кн. 1, s-элементы. -305 с.

21. Особенности распределения химических элементов в талой воде ледника Большой Актру (Горный Алтай) / Л.П. Рихванов, Ю.В. Робертус, А.В. Таловская, Р.В. Любимов, А.Ю. Шатилов // Изв. ТПУ. - 2008. - Т. 313. - № 1. - С. 97-103.

22. Ялалтдинова А.Р. Элементный состав растительности как индикатор техногенного воздействия на территории г. УстьКаменогорска: дис...канд. геол.-минерал. наук. - Томск, 2015. $-172 \mathrm{c}$

23. Робертус Ю.В., Рихванов Л.П., Любимов Р.В. Дендрогеохимическая индикация трансграничных переносов экотоксикантов на территорию Алтая // Известия ТПУ. - 2010. - Т. 317. № 1. - C. 173-177.

24. Кац В.Е. Распределение таллия в компонентах окружающей среды Республики Алтай // Экология и охрана окружающей среды: Тез. докл. IV Всеросс. науч.-практ. конфер. - Рязань, 1994. - C. 139-141.

Поступила 14.11.2019 2.

\section{Информация об авторах}

Робертус Ю.В., кандидат геолого-минералогических наук, ведущий научный сотрудник, Институт водных и экологических проблем СО РАН.

Рихванов Л.П., доктор геолого-минералогических наук, профессор отделения геологии Инженерной школы природных ресурсов, Национальный исследовательский Томский политехнический университет.

Юсупов Д.В., кандидат геолого-минералогических наук, доцент кафедры геологии и природопользования, Амурский государственный университет.

Любимов Р.В., кандидат геолого-минералогических наук, научный сотрудник, Институт водных и экологических проблем СО РАН.

Кивацкая A.B., кандидат геолого-минералогических наук, старший научный сотрудник, Институт водных и экологических проблем СО РАН.

Cитникова B.A., кандидат геолого-минералогических наук, научный сотрудник, Алтайский региональный институт экологии.

Большунова T.C., кандидат геолого-минералогических наук, ведущий инженер АО «ТомскНИПИнефть». 
UDC 550.47:504.7:582.29(571.150)

\title{
ELEMENTAL COMPOSITION OF LICHEN (Rhizocarpon) ON STONE AS AN INDICATOR OF POLLUTANT TRANSPORT TO THE ALTAI TERRITORY
}

\author{
Yuriy V. Robertus ${ }^{1}$, \\ ariecol@mail.gorny.ru \\ Leonid P. Rikhvanov², \\ rikhvanov@tpu.ru \\ Dmitry V. Yusupov3, \\ yusupovd@mail.ru

\section{Roman V. Lyubimov1,} \\ ariecol@mail.gorny.ru \\ 1 Institute for Water and Environmental Problems SB RAS, \\ 1, Molodezhnaya street, Barnaul, 656038, Russia. \\ 2 National Research Tomsk Polytechnic University, \\ 30, Lenin avenue, Tomsk, 634050, Russia. \\ 3 Amur State University, \\ 21, Ignatievskoe highway, Blagoveshchensk, 675027, Russia. \\ 4 Altai Regional Institute of Ecology, \\ 54, Zavodskaya street, Maima, Altai Republic, 649100, Russia. \\ 5 Tomsk Oil and Gas Research and Design Institute, \\ 72, Mira avenue, Tomsk, 634027, Russia.
}

\author{
Anna V. Kivatskaya ${ }^{1}$ \\ ariecol@mail.gorny.ru
}

Valentina A. Sitnikova 4 , valya_90_well@mail.ru

Tatiana S. Bolshunova 5 , BolshunovaTS@gmail.com

Relevance of the work is caused by the need to study the environmental consequences of long-term transboundary transport of pollutants from industrial centers of East Kazakhstan to the Altai region and Altai Republic.

The main aim of the research is to study the elemental composition and features of its distribution in the epilitic lichen Rhizocarpon geographicum (L.) DC. on stone as a biogeochemical indicator of the specificity and intensity of transboundary transport of pollutants to the Altai territory.

The methods: selection of samples of lichen Rhizocarpon geographicum (L.) DC. on rock outcrops of lower Paleozoic terrigenous rocks to determine the content of mercury and 28 chemical elements by atomic absorption and instrumental neutron activation analysis, processing the data by methods of applied statistics.

The results. The authors have obtained the data on the levels of content and distribution characteristics of the complex chemical elements in the lichen Rhizocarpon geographicum (L.) DC. on stone on the territory of Altai. They were compared with the regional background and Clark in the biosphere. The presence of two groups of elements in the lichen - trace elements of inorganic dust and the Association of elements of polymetallic ores ( $\mathrm{Zn}, \mathrm{As}, \mathrm{Sb}, \mathrm{Br}, \mathrm{Hg}, \mathrm{Au}$ ) was established. The argument in favor of the predominant receipt of elements of this Association in the lichen Rhizocarpon from atmospheric deposition transferred from the territory of East Kazakhstan was given. The authors identified the large area of elevated concentrations of the studied elements in Rhizocarpon, spatially coinciding with the previously established area of snow and vegetation contamination in the region. They made the conclusion on suitability of the elemental composition of epilitic lichen Rhizocarpon on stone as a biogeochemical indicator of the specificity and intensity of transboundary transport of pollutants to the Altai territory.

Key words:

The Altai mountains, transboundary transfer, the lichen Rhizocarpon on stone, elemental composition, biogeochemical indicator.

\section{References}

1. Kuznetsova V.F. Epifitnye lishayniki kak indikatory zagryazneniya atmosfernogo vozdukha gazoobraznymi pollyutantami, tyazhelymi metallami $i$ radionuklidami. Avtoreferat Diss. Kand. nauk [Epiphytic lichens as indicators of air pollution with gaseous pollutants, heavy metals and radionuclides. Cand. Diss. Abstarct]. Nizhny Novgorod, 2004. 24 p.

2. Richardson D.H.S. Pollution monitoring with lichens. Naturalists handbooks. Slough, Richmond Publishing, $1992.19 \mathrm{p}$.

3. Safrankova E.A. Kompleksnaya likhenoindikatsiya obshchego sostoyaniya atmosfery urboekosistem. Diss. Kand. nauk [Complex lichen indications of the general condition of the atmosphere of urban ecosystems. Cand. Diss.]. Bryansk, 2014. 204 p.
4. Richardson D.H.S. Understanding the pollution sensitivity of lichens. Botanical Journal of the Linnean Society, 1988, vol. 96, pp. 31-43.

5. Bolshunova T., Rikhvanov L. , Mezhibor A., Zhornyak L., Baranovskaya N., Eremina E. Biogeochemical characteristics of epiphitic lichen Lobaria pulmonaria of the Barguzin nature reserve (the Republic of Buryatia, Russia). Journal of Environmental Engineering and Landscape Management, 2018, vol. 26, no. 2, pp. 120-127.

6. Robertus Y.V., Rikhvanov L.P., Sitnikov A.V., Savenko K.S., Bolshunova T.S. Elemental composition of the lichen on the slate as bioindicator of air pollution of the Metropolitan area the city of Gorno-Altaysk. Bulletin of the Tomsk Polytechnic University. Geo Assets Engineering, 2018, vol. 329, no. 4, pp. 70-78. In Rus. 
7. Bargagli R. Moss and lichen biomonitoring of atmospheric mercury: a review. Science of the Total Environment, 2016, vol. 572, pp. 216-231.

8. Conti M.E., Cecchetti G. Biological monitoring: lichens as bioindicators of air pollution assessment - a review. Environmental Pollution, 2001, vol. 114 (3), pp. 471-492.

9. Rossbach M., Lambrecht S. Lichens as biomonitors: global, regional and local aspects. Croatica Chemica Acta, 2006, vol. 79 (1), pp. 119-124.

10. Kostryukova A.M., Krupnova T.G., Mashkova I.V., Schelkanova E.E. Monitoring air quality using lichens in Ghelyabinsk, Russia Federation. International Journal of GEOMATE, 2017, vol. 12, no. 34, pp. 101-106.

11. Purvis O.W., Williamson B.J., Spiro B., Udachin V., Mikhailova I.N., Dolgopolova A. Lichen monitoring as a potential tool in environmental forensics: case study of the $\mathrm{Cu}$ smelter and former mining town of Karabash, Russia. Geological Society, London, Special Publications, 2013, vol. 384, pp. 133-136.

12. Bozkurt Z. Determination of airborne trace elements in an urban area using lichens as biomonitor. Environmental monitoring and assessment, 2017, vol. 189, no. 11, pp. 1-12. DOI: 10.1007/s10661-017-6275-x

13. Vasilevich M.I., Vasilevich R.S. Features of heavy metal accumulation by epiphytic lichens in background areas of the taiga zone in the European northwest of Russia. Russian Journal of Ecology, 2018, vol. 49, no. 1, pp. 14-20.

14. Koroleva Y., Revunkov V. Air pollution monitoring in the southeast Baltic using the epiphytic lichen Hypogymnia physodes. Atmosphere, 2017, vol. 8, no. 7, pp. 1-12.

15. Will-Wolf S., Jovan S., Amacher M.C. Lichen elements as pollution indicators: evaluation of methods for large monitoring programmes. The lichenologist, 2017, vol. 49, no. 4, pp. 415-424.

16. Boonpeng C., Polyiam W., Boonpragob K., Sriviboon C., Sangiamdee $\mathrm{D}$., Watthana $\mathrm{S}$. Assessing atmospheric pollution in a petrochemical industrial district using a lichen-air quality index (IIAQI). Ecological indicators, 2018, vol. 95, pp. 589-594.

17. De Nicola F., Adamo P., Giordano S. Comparison of lichen and moss bags as monitoring devices of airborn trace elements and PAHs. Biomonitoring of air pollution using mosses and lichens: a passive and active. Approach state of the art research and perspectives. New York, Nova Science Publishers, 2016. pp. 177-194.

18. Danilova N.G., Chapaeva G.V. Ekologicheskiy monitoring sostoyaniya okruzhayushchey sredy Vostochno-Kazahstanskoy oblasti v 1999 godu [Ecological monitoring of the state of the environment of the East Kazakhstan region in 1999]. Nash obshchiy dom. Mezhdunarodnaya konferentsiya [Our Global Neighbourhood. The international conference]. Barnaul, Publishing house of ASU, 2000. pp. 27-29.

19. Robertus Y.V., Udachin V.N., Rikhvanov L.P., Kivexa A.V., Lyubimov R.V., Yusupov D.V. Indication of the environmental components of the transboundary transfer of polluting substances on the territory of the Altai mountains. Bulletin of the Tomsk Polytechnic University, 2016, vol. 327, no. 9, pp. 39-48. In Rus.

20. Ivanov V.V. Ekologicheskaya geokhimiya elementov: spravochnik [Environmental Geochemistry of elements: handbook]. Moscow, Nedra Publ., 1994. 304 p.

21. Rikhvanov L.P., Robertus Y.V., Talovskaya A.V., Lyubimov R.V., Shatilov A.Y. Features of distribution of chemical elements in melt water of the glacier Bolshoy Aktru (Altai Mountainous). Bulletin of the Tomsk Polytechnic University, 2008, vol. 313, no. 1, pp. 97-103. In Rus.

22. Yalaltdinova A.R. Elementny sostav rastitelnosti kak indikator tekhnogennogo vozdeystviya na territorii g. Ust-Kamenogorska. Avtoreferat Dis. Kand. nauk [Elemental composition of vegetation as an indicator of anthropogenic impact on the territory of UstKamenogorsk. Cand. Diss. Abstract]. Tomsk, 2015. 172 p.

23. Robertus Y.V., Rikhvanov L.P., Lyubimov R.V. Dendrochemistry indication of cross-border transfers of toxicants to the Altai territory. Bulletin of the Tomsk Polytechnic University, 2010, vol. 317, no. 1, pp. 173-177. In Rus.

24. Katz V.E. Raspredelenie talliya v komponentakh okruzhayushchey sredy Respubliki Altay [Thallium distribution in the environmental components of the Republic of Altai]. Ekologiya i okhrana okruzhayushchey sredy. IV Vserossiyskaya nauchno-prakticheskaya konferentsciya [Ecology and environmental protection. IV sciencepractical conference]. Ryazan, Publishing house of RSU, 1994. pp. 139-141.

Received: 14 November 2019.

\section{Information about the authors}

Yuriy V. Robertus, Cand. Sc., leading researcher, Institute for Water and Environmental Problems, Siberian Branch, Russian Academy of Sciences.

Leonid P. Rikhvanov, Dr. Sc., professor, National Research Tomsk Polytechnic University.

Dmitry V. Yusupov, Cand. Sc., associate professor, Amur State University.

Roman V. Lyubimov, Cand. Sc., researcher, Institute for Water and Environmental Problems, Siberian Branch, Russian Academy of Sciences.

Anna V. Kivatskaya, Cand. Sc., senior researcher, Institute for Water and Environmental Problems, Siberian Branch, Russian Academy of Sciences.

Valentina A. Sitnikova, Cand. Sc., senior researcher, Altai Regional Institute of Ecology.

Tatiana S. Bolshunova, Cand. Sc., engineer, Tomsk Oil and Gas Research and Design Institute. 